\title{
Effective Teaching Strategies to Eliminate Spelling Problems Among Saudi English Language Undergraduates
}

\author{
Dheifallah Altamimi ${ }^{1}$ \& Radzuwan Ab Rashid ${ }^{2}$ \\ ${ }^{1}$ University college of Haqel, Tabuk University, Tabuk, Saudi Arabia \\ ${ }^{2}$ Faculty of Languages and Communication, University Sultan Zainal Abidin, Terengganu, Malaysia \\ Correspondence: Radzuwan Ab Rashid, Faculty of Languages and Communication, University Sultan Zainal, \\ Abidin, Terengganu, Malaysia. E-mail: radzuwanrashid@unisza.edu.my
}

Received: June 4, 2019 Accepted: July 5, 2019 Online Published: September 6, 2019

doi:10.5539/ijel.v9n5p317 URL: https://doi.org/10.5539/ijel.v9n5p317

\begin{abstract}
Saudi university students who learn English as a foreign language face multiple difficulties during the process of learning especially while mastering writing skill and its component (spelling). This paper aims to explore the most recommended teaching strategies to eliminate the Saudi university students' spelling errors. The research participants were 15 students in English Language Department at Tabuk University and 15 English language lecturers from the same department. Group structured interviews were designed for the lecturers and students. The findings reveal that, there are different effective teaching strategies to master English spelling such as, practicing spelling, lecturers' pedagogical practices and Learners' Engagement. This paper concludes that, the spelling problems of EFL learners could be addressed by a variety of intervention strategies such as, instructors should be introduced to a range of teaching methods such as simulation situations where they can experience problems arising from poor spelling and roleplaying .Students should also be encouraged to engage in the learning process by setting tasks like, learning the spelling of a few selected words, which they can test each other on in pairs class and so evaluate their own and their peer's work. This paper hoped that, the findings revealed in this study will help the policymakers in taking necessary actions in improving the learning experience of Arab learners of English.
\end{abstract}

Keywords: accurate spelling, EFL learners, learning spelling, spelling problems

\section{Introduction}

Language serves as the principal source of communication. Through this channel, individuals are able to share their ideas and thoughts with others. Arbib (2005) states that human beings are distinct from animals due to their ability to communicate through the written language. Thousands of languages are used in the world as a medium of communication within and between groups, and they vary according to their location, their regions or countries. The extent to which a specific language is spoken depends on the people using it; some languages are lingua francas (like English or Spanish) and widely used by thousands of people, while others have only a few speakers; Sami has about 300 speakers in Norway Sweden and Finland, who are mainly semi-nomadic reindeer herders.

In consideration of the importance of learning the English language for education and employment, learning the four English language skills is compulsory for learners to use the language correctly in order to share learners' ides and thoughts, and the negative effects of being unable to use the language well and master the language skills, it can be stated that the English wiring system (spelling) creates a problem for most learners.

Writing can transform spoken words into knowledge which is captured in time (unlike speech, which is transient) and can be seen and read, not only heard. Whether English is a second or foreign language, it is challenging for the learner to represent it in a written script. According to Al-Jarf (2007), in the context of Saudi EFL and language instruction, developing writing skills poses various challenges while Shukri (2014) claims that Arab EFL learners are stereotyped as having inadequate writing skills. Arabs as second language learners make lots of errors while writing in English, and these errors are considered too seriously confuse many native speakers. Arab EFL/ESL learners are likely to discuss one point several times from different angles, which has the potential to confuse the native English reader (Rahman \& Alhaisoni, 2013) who expects a more direct approach (calling a 
spade a spade rather than an implement for earth removal in small amounts).

Nonetheless, the procedure is relatively more complicated for Arab learners due to the linguistic difference between their native language i.e., Arabic, which has a different writing and spelling system from English. Consequently, it is expected that the spelling errors made by Arabic learners may differ from those of learners with other language backgrounds (for example, German or Latin-based languages) and therefore, teaching Arab Learner of English could also be different. Therefore, there is a need to study and have a closer look at the particular challenges which Arab learners of English have to face in general, and Saudi university students, in particular. The reasons and consequences cannot be derived from previous studies, which either included only school students or a mix of students with different language backgrounds. This research paper could help provide insights and more knowledge about the most effective teaching or learning strategies to address Arab students' problems in English spelling in effective way.

Shukri (2014) points out that the writing errors or difficulties encountered by Arab students can be linked to several factors. One is the nature of the EFL context, which has limited resources and opportunities for practicing the L2. Additionally, L1 interference can be seen as cultural resistance, lack of motivation, the type of curriculum, traditional methods of instruction which emphasize the teacher's role and rote memorization as learning are all considered the main reasons why Saudi students' struggle with their writing skills in English. Al-Seghayer (2011) states that Saudi students were ranked 39 out of 40 in a report published by the Cambridge Examination Center in 2009. This report gave the proficiency level of ESOL students in 40 countries, including England, Spain and Hong Kong. Garmi (2010) also adds that on the IELTS test report, Saudi students' results showed that while their average scores in listening, speaking, and reading were low, the average scores for the writing section were even lower (Javid et al., 2013).

\section{Literature Review}

Spelling is considered an essential component of written language. The potential mistakes in written spellings may change the meaning and understanding of written material and would make it unclear. Hence, it is important to use the correct spelling of words in order to convey the exact intended meaning of the content. In this context, Babayiğit and Stainthorp (2010) state that grammatical and phonological skills make a major contribution to spelling performance. Therefore, it can be asserted that spellings play a pivotal role being a primary and essential skill required by students. Accurate spelling enables writers to express their ideas and thoughts within a standard framework which is easily understandable by their readers. For effective writing, spelling must also be effective.

English spelling in general presents problems because of the contrasts between the sounds of letters or groups of letters and the various ways they can be written down, for instance, him and hymn have the same pronunciation $(/ \mathrm{hlm} /)$, which makes it difficult for learners to spell correctly. There is no direct link between the pronounced and written form in many cases, so these numerous dissimilarities appear arbitrary and why words are spelled the way they are is difficult to understand, so non-English speaker learner can be confused by the lack of connection between the spelling of a word and its pronunciation. In a perfectly consistent system of spelling, there would be one symbol for each phoneme. It is immediately obvious that present-day English, being a hybrid language, with borrowings and influences from many other languages, is very far from this. For example, the central schwa vowel $[\partial]$ is represented in many different ways, as illustrated by the bold letters in the following words: about, father, neighbor, pleasure, the, theatre. On the other hand, the written letter "a" is used to represent several entirely distinct sounds, such as those in "about, gate, cat, father, talk".

Although, spelling in English is alphabetical, the same letters representing the sound of a word in the language can often be used in different ways. These overlapping occurrences are usually decided by a language rule, but in some cases, they are non-systematic and their pronunciation has to be learned separately. English spellings can be classified into three categories:

1) Words which are commonly used, regular and their pronunciation can be accessed from basic knowledge about the phoneme-grapheme relationship, such as tin, pet, fat, and bad.

2) Irregular words whose pronunciation can be predicted from knowledge of rules, for instance, $/ \mathrm{k} / \mathrm{spelt}$ with a $\mathrm{k}$ before e and i, as in kill and key but otherwise with a c, as in car and course.

3) The third category of spelling is most challenging to pronounce as it is irregular and unpredictable, for instance, yacht, catch, and drawn.

Carney (2012) claims that there is a very close fit between English spelling and pronunciation; he asserts that while spelling and pronunciation vary to some extent, and these variations are an essential component of English spellers' competencies. Toutanova and Moore (2002) point out that there are degrees of harmfulness in spelling 
errors according to the purpose of communication. First of all, relatively harmless errors do not create confusion with other words as to what is being signalled: e.g., dout for doubt. Second, more harmful error can cause word confusion, particularly in isolation: e.g., bear for bare. Thirdly, the most harmful spelling errors create either a nonexistent word or the wrong one: e.g., bology for biology, or sediment for sentiment. An awareness of these levels of spelling errors when appraising student's spelling, particularly in daily writing situations, helps to put seriousness of students' spelling errors in a more appropriate perspective. But, of more importance, analyzing the kinds of errors made can reveal the student's development in spelling that may need strengthening or remediation.

Recent investigations, such as by Bisani and Ney (2008) and Ehri (2013) have also produced significant evidence indicating that the spelling attempts children make are not random, but they seem to follow an orderly sequential progression which depends upon the level of sophistication of the child's abstract phonological system and his/her ability to integrate other sources of English orthography. In other words, spelling is more than a simple match between graphemes and phonemes to find the pronunciation of a word from its written form or vice versa.

\subsection{Raising Awareness of Spelling Rules}

Shintani, Ellis and Suzuki (2014) believe that the main spelling errors are caused by the non-phonetic aspect of parts of the English language. However, English is not so non-phonetic that it cannot be learned by students. Apart from the regular sounded elements, Liton (2013) argues that the foundation of spelling rules and instruction can help Arab students learn the patterns of English language and reduce the likelihood of spelling errors. English classes should devote time to teaching spelling to reassure students and support them with knowledge, understanding, while dispelling any misconceptions about the link between phonetic sounds of English and their written representations.

Several studies demonstrate that irregularity of the English writing system is one of the foremost causes of confusion for Saudi university (Al-Seghayer, 2014; Al Khasawneh, 2014; Tamran, 2016; Al-Sobhi, Rashid, Abdullah, \& Darmi, 2017). These irregularities are apparent in the spelling system of English language. O'Grady et al. (1999) categorise the spelling irregularities into five. The cause of spelling irregularities is silent letters of English. English language contains some silent letters that are written and not spoken for example the letter $\mathrm{g}$ in sign and k in knife. Second, in English language a group of two or more letters can be used to represent a single segment such as th in think. Third category includes a single letter can represent a cluster of two or more segments such as $\mathrm{x}$ in saxophone. Fourth, the same letter can represent different segments in different words such as $\mathrm{i}$ which is pronounced as /I/ in give but as /aI/ in five. And fifth, includes the same segment can be represented by different letters in different words such as /u:/ which is represented differently in rude, loop, soup, and sue.

Sarantakos (2012) adds that teaching how to avoid spelling errors not only helps students reduce their spelling errors but also improves their performance in both reading and writing. Sawalmeh (2013) points out that English spelling rules include some frequent patterns that have a level of consistency, which must be part of the course syllables. These patterns support the students by providing a constant basis for how the different sounds can be spelled. The rules also provide the significant information to the student for understanding that English has letters that are silent, or unpronounced, but represented in writing (Al-Khasawneh, 2014).

Additionally, Shintani, Ellis and Suzuki (2014) point out that, intonation and stress influence a word's pronunciation, but does not affect the word's spelling and further conclude that the lexical spellings signify meaning-bearing items directly and the phonetic aspect is irrelevant to their identification. Research into the relationship between sounds and spelling suggests that it is necessary to understand the basic principles of phonics and the written form of high frequency words in order to minimize writing errors. The literacy skills usually begin orally with words and develop into awareness of the phonological relationships. Later, these skills move towards the encoding and decoding of synthetic phonics, which is the synthesizing or blending of the phonemes within a word that helps the student to read the word and then spell it properly without missing out letters. The student can read words with similar spellings quickly. Al-Shormani and Al-Sohbani (2012) suggest that memory is not a sufficient tool to ensure the knowledge of correct spellings lasts or is and meaningful; they need practice. University teachers need to organize different types of activities that engage the students in wanting to write correctly, such as spelling contests, or essay writing challenges. Spelling mistakes can further help instructors to assess their students' abilities and group them according to their spelling and learning skills levels.

Wang and Jiang (2015) explain that students' ability to learn also depends on the systematic and organised 
structure of the teaching process. It is vital for students to be able to identify the sound-letter relationships and have an in-depth awareness of spelling rules. Vocabulary rounds, comprehension strategies, and regular and consistent teaching of these assist in developing the learners' competence and understanding of the importance of spelling and writing rules. The rules also identify fixed patterns within the English language; for instance, written letter "c" is pronounced as $/ \mathrm{k} /$ except when followed by written letters e or $\mathrm{i}$. In this case, it is pronounced $/ \mathrm{s} /$. The students need to pay close attention to vowels and the environment in which they appear. Other studies also refer to significant rules such as these as necessary for reducing errors and mistakes in writing (Liton, 2012).

Kang and Han (2015) developed a complete list of spelling rules that are considered by the instructors in Saudi universities to develop efficient awareness and understanding in Arab students (See Appendix A). Shintani and Ellis (2013) point out that English rules are varied with many exceptions, which makes it difficult for the beginners to remember them all or quickly. So, instructors should give Arab students the opportunities to discover the rules for them to avoid making spelling mistakes and broaden their horizon of thinking, understanding as well as their ability to evaluate to decide how to spell in English (Al-Nafiseh, 2013).

\subsection{Spelling Structure Techniques}

Liton (2013) suggests that teachers and instructors are responsible for developing and forming the techniques that improve students' spelling capabilities and competencies. There are different and distinct spelling contexts that require different instruction techniques and approaches. By assessing and evaluating students' spelling errors, teachers can identify, design and implement the appropriate activities and learning exercises to respond to the complexities of English spelling. Alhaysony (2012) suggests instructors motivate Arab students to keep personal and individual spelling books in order to keep a proper record of their spelling mistakes and their corrections so they can easily refer back to them when they meet the word again and to help them remember correct forms. The study also advised the instructors and teachers to develop the habit of regularly proofreading their work before submitting it.

Javid and Umer (2014) also contribute useful suggestions for correcting the spelling mistakes made by students in writing in a second or foreign language. Firstly, reading is the best way to reduce the difficulty of spelling English words. Jahin and Idrees (2012) suggest silent reading increases the exposure of the student to understanding new things, while reading aloud also plays a significant role in linking spelling to the appropriate phonic sounds. The technique of reading aloud can help Arab students pay more attention to the word structure. Secondly, it is necessary for learners to know the meaning of the words they are learning or reading (Al-Khasawneh, 2014). Learning will not be effective or successful until the students show interest in and practice using words both orally and in written format. Furthermore, the division of words into morphemes and phonemes is also an effective technique that reduces the students' misconceptions of the errors they made and about English rules and guidelines. Making the correspondences between different words would make it easier for students to pronounce them correctly and eliminate the errors while writing them (Alkhatnai, 2012).

In order to spell the words seen in text properly students need to rely heavily on their visual memory. Arishi (2012) advises teachers and course instructors to assists foreign students in every possible manner to learn the words they are struggling to learn. The instructor must develop different activities to overcome or solve their problems with spelling and written problems (Rajab, 2013). Another way the teacher can guide the students is by underling the inaudible and soundless letters in words, such as psycho, weigh, and sight. Furthermore, the teacher must underline the students' spelling mistakes to find out their different areas of difficulty and mistakes should be written on the board beneath the correct spelling, so students can see the differences. Moreover, teachers must give all the students equal chances and opportunities to contribute the new words to improve their learning and knowledge. Teachers should also develop a conceptual context to generalize and show the reasoning behind spelling to help the students' upgrade their understanding and awareness.

Al-zuoud and Kabilan (2013) recommend that language instructors show the derivation of words and the rules for affixes. The instructor should offer complete guidance for students to practice and observe listening for onomatopoeia, for instance and how to divide long words into familiar chunks while developing awareness of the common arrangement of letters play a huge part towards learning how syllabification works. The preparation and development of writing competitions also motivates the students to develop the competences to deal with spelling.

\subsection{Developing Spelling Skills}

In learning to spell, there are four different forms of development pathway; etymological, phonological, morphemic, and visual that can increase the spelling awareness of students in Saudi universities (Polio, 2012). However, Al-Seghayer (2014) suggests that students who need additional or extra support their teachers should 
be supported by different types of development programs or activities. The development programs can increase students' awareness of word patterns based on the above four different categories of spelling knowledge (Jahin, 2012). According to Kang and Han (2015), the systematic teaching of spelling should include strategies, guidance and most importantly, independent practice. The study also concluded that the teacher is accountable for assessing and examining why words are misspelled to instigate teaching about spelling patterns and their application.

Sawalmeh (2013) mentions the need for an effective format for planning, organizing and systematically spelling teaching a spelling program. Language development programs must focus on the student's current level of performance in English and what they need to improve their spelling. The program must explicitly and systematically teach spelling patterns and teach chunks that are easier for students to remember long term (Meng, 2017). Simultaneously, the development skills program or activities must offer opportunities for growth as well as giving sufficient feedback on students' regular practices.

Additionally, the programs and activities need to review and practice words that were learned in previous sessions. Constant revision of the correct pronunciation and spelling of words helps students to remember them and reduces the chance of serious errors in writing. Similarly, Sarantakos (2012) adds that development programs should simplify and make general the learning of spelling skills for students of Saudi universities and emphasize the importance of correct spelling for both personal and professional growth. Daif-Allah (2012) further adds that the development programs should include dictionary and vocabulary skills as these can help integrate all the important dimensions of learning.

\subsection{Considerations for Teaching Spelling}

Al-Seghayer (2014) postulates that there are certain concerns that needs to be satisfied in order to develop the spelling skills of students. These include the teacher's role in selecting words and word groups that help the students keep track of similarly spelled words and so avoid errors. It is essential to prioritise words that Saudi university students must recognise and spell correctly. Teaching words by breaking them into phonemes and morphemes or-like affixes - can help students memorize words better. At the early stage of learning English, instructors should teach a few new words each class, three to five, rather than 10 or 15 as this could become arduous and boring for the students.

Furthermore, teachers should offer any additional support and encouragement needed by students during each learning phase. Teachers need to take account of any external factors like general tests and examinations to ensure students have provide the necessary skills, strategies, and knowledge, but more importantly, those that make the students more effective and successful learners. Regular classroom activities and language sessions must provide opportunities to deal with difficulties in reading, writing and spelling. Assessment and regular monitoring play a significant role in achieving better results and outcomes and help the instructor evaluate the performances of the students individually and see whether the students are making progress. Kang and Han (2015) argue that language instruction can increase the knowledge, skills and abilities of students to learn how to use the appropriate rules in English language and thus use the language for study or work purposes. Teachers need to communicate through dialogue sessions with their students, as this is are considered critical for success.

Another way to encourage and motivate the students is journal writing for at least ten minutes a day where students record their reflections, ideas and thoughts in writing, and illustrations. This activity helps students understand the connections between different words and acquire the skill of spelling words correctly. In addition to motivation, positive feedback, praise and admiration for the students' efforts-including their journal homework efforts are necessary to engage the students' enthusiasm and help them focus on the areas to be learned (Sharma, 2015). Making activities that are enjoyable for the students, like spelling tests or verses, also foster positive outcomes that make spelling more meaningful for students. Dictionary and vocabulary training can provide the students with guidance from other effective and authoritative sources to reduce spelling errors and which can be used autonomously outside the classroom.

Knowing the correct spellings, meanings and definitions of words are highly informative sources of information about learning the new language. For instance, common letter combinations, high frequency words, word origins like Latin or Greek roots in legal, medical, or scientific areas. Javid and Umer (2014) point out that it is also important for caregivers and parents to support Arab learners in their learning of the English language. Those parents with knowledge of English can help the performance of their Saudi children. Systematic tracking of student progress at school level would allow interventions to be made at appropriate times so high levels of improvement could be achieved (Al-Sohbani \& Muthanna, 2013). 


\section{Methodology}

This research paper employs case study approach. Data were gathered through structured group interviews with the students who are in the final year of their degree in English language at university college of Haqel and their instructors. 3 group interviews are used in this study for the students (A, B, C) in each group five students. In addition, three group interviews were also used in this study for the lecturers, whereas in each group consist of five lecturers. All the interviews were recorded, analyse and codes manually. For example, (S1/GA) means student number 1 from group A and (L2/GB) means lecturer number 2 from group B.

\section{Findings}

\subsection{Students' Views}

Different students from different groups sheared their views and comments, in order to recommend an effective teaching or learning strategies to eliminate their spelling errors. For example; practicing spelling and seeking external helps and sources.

Saudi students can improve their spelling by practicing the skill of writing frequently about different topics $(S 1 / G A)$. This perceptive comment lays emphasis on learning spelling through regular written practice in using the vocabulary of different subjects in context (rather than learning the spelling of new words individually, by heart, without a context) — good advice, indeed. Devonshire and Fluck (2010) stated that spelling rules can be learnt if students make extra efforts.

Saudi students can also use the reading aloud strategy to make themselves familiar with the correct pronunciation (S2/GA). This comment links oral/aural skills and spelling. Oral spelling tests can help learners connect phonemes with graphemes and reading written scripts aloud can help their authors to identify common mistakes. Conrad (2008) suggested that reading and critical evaluation or peer evaluation of scripts can be an effective way of identifying spelling mistakes - also pronunciation errors.

Students must be aware of the term morphemes and know the different types of morphemes, for example: derivational and inflectional morphemes so they can use the right prefix and suffix while writing $(S 3 / G B)$. This comment reveals abstract knowledge of structural concepts that are not difficult to memorize but require efforts. Fresch (2007) found that English instructions are difficult but not impossible to memorize especially learning morphemes.

Students can break long words into more than one part or syllable in order to make the words more understandable to spell and write (S4/GB). Reed's (2012) study revealed that breaking long words into syllables could help students to learn difficult spellings, like diff-i-cul-ty.

Students can also practice difficult words before the exams to avoid losing marks in their exams $(S 1 / G C)$. Some students seemed reluctant to adopt strategies on their own. The views suggested that students have various reasons for having difficulty learning English spellings, but using the right strategy at the right time - like practicing and writing difficult words before exams - can pay dividens. Reed (2012) found that practicing difficult words and writing them down several times can improve the writing in English scripts.

Students must use the strategy of proofreading after any written task, to help them discover their spelling errors and correct them before submitting their papers to the lecturers (S2/GC). Adopting strategies such as proofreading and reading aloud to identify mistakes can help students a lot. O'Brien's (2015) study revealed that proofreading is one of the most effective ways of improving spelling related issues.

Students can memorize the shape of difficult words if they are not familiar with the spelling rules by saving the difficult or long words by heart $(S 3 / G C)$. Memorizing the shape of the words can to avoid spelling mistakes. Moats (2005) found that memorizing the shape of words could help EFL students to overcome their spelling concerns and errors.

The students must develop phonemic awareness, where the students understand letter-sound correspondence and the individual parts that make up words $(S 4 / G C)$. Spelling/sound correspondences can be an effective way for students to learn how to spell words. Brice and Brice's (2009) study revealed that phonemic awareness could help students to overcome their common spelling issues and challenges.

Students can listen to each sound in a word and to represent each sound with a letter or combination of letters $(S 5 / G C)$. Listening is also an effective way to learn how to pronounce words according to their spelling and to write down the spelling of words listened to. Moats' (2005) study revealed that listening and writing words down accordingly is an important strategy.

Students need to keep practicing the spelling rules and learn from their spelling mistakes (S5/GA). Again, the 
student sees practice can help students to overcome their writing challenges, as also found by Reed (2012), that practicing helps improve spelling skills and even complex spellings can be learnt with proper training as found in Conrad's (2008) study, that rewriting complex words can help the learning of difficult words.

Internet sources can be helpful to learn new spellings and increase self-learning. Online quizzes could be explored regarding spelling rules, so the students can practice their writing and learn from their spelling mistakes using the strategy of self-learning or study (S1/GA). In addition, students can read electronic newspapers, and copy new words that will help them to remember the spelling of new words from different fields $(S 2 / G A)$. Electronic sources, mainly newspapers, can be effective for increasing knowledge as well as vocabulary, according to El-Dakhs and Mitchell (2011) who suggest that copying new words from different topics can help learners reduce their spelling mistakes.

A participant from Group A recommended that students must use different types of dictionaries like English -Arabic and English to English in order to know the correct spelling and to increase their store of new vocabulary $(S 3 / G A)$. Dictionaries are one of the useful sources for improving academic skills in general. El-Dakhs and Mitchell (2011) point out that regular use of dictionaries will increase the learners' vocabulary and improve their spelling.

A participant from Group B suggested that students can read subtitles in movies that can help them to improve their English reading skills as well as learn the correct spelling from the visual aid subtitle spelling strategy $(S 1 / G B)$. External sources like watching movies with subtitles is an effective strategy for learning new spellings. El-Dakhs and Mitchell (2011) claim that watching movies with subtitles can increase the learners' knowledge of any foreign or second language.

\subsection{Lecturers' Views}

Lecturers shared multiple effective teaching strategies to address Saudi students' spelling problems. For example; lecturers' pedagogical practices and strategies and Learners' Engagement.

The participants from Group A had suggestion. For example, a participant from Group A reported that, the lecturer must ask students to come and write on the board regularly and the lecturer must assign writing assignments every day to. Also, lecturers must ask students to copy down new words they learn into their notebooks as a general practice in the classroom $(L 1 / G A)$. The participant suggests that in Tabuk University, currently the lecturers teaching English are more likely to carry out monologues or one-way communication in the classroom, although asking individuals to write on the board could be seen as a sharing strategy to invite comparisons or comments. However, in future, it might be more productive if students play a more dialogic, interactive role by giving presentations or assigning group activities and using multi-media resources. Similar comments came from two participants from Group A for example; the lecturers must let the students write words/phrases again and again in order to learn spelling. This will not only improve their spellings but it will also help them to hone their writing skills. By doing things repeatedly helps them to memorize them as well. Their handwriting will also be improved and it will make them more proficient in the English language (L2/GA). Also, the lecturer must draw students' attention to irregular spelling and silent letters during their daily lessons, especially during the reading section of classes (L3/GA).

The response from the participants links repetition to memory, spelling and writing. Liu (2017) also found similar suggestions when examining the writing strategies implemented by lectures to teach English. Pointing out the link between irregular spelling, silent letters and reading resonates with Pieretti and Roseberry-McKibbin's (2016) study of language impairment which found it was the responsibility of the teacher to draw the students' attention to spelling errors.

Different comments from the lecturers regarding the lecturers' pedagogical practice to help the Saudi students to address their spelling problems such as, the lecturers must draw the student's attention on letters that are not found in Arabic, such as $P$ and $V$ in terms of the difference between English and Arabic (L4/GA). And the lecturer must ask students to practice spelling words they misspell by copying them out a few times in order to make sure that the students practice the correct of words which they misspelled before (L5/GA). The response from above participants about focusing on the differences between Arabic and English and emphasizing on the practicing and repetition of the correct spelling until the students can remember the correct spelling. This resonates with Mukminin, Ali and Ashari's (2015) study of English academic learning programmes in a Nigerian University, which found that teachers must guide students clearly about the main differences between Arabic and English, which can ease the entire learning process. Also, Pieretti and Roseberry-McKibbin (2016) concluded that lectures need to ask students to write words down again and again so that they can reduce their spelling errors. 
The participants from all the groups (A, B and C) shared different comments and suggestions regarding the learners' engagement into the learning environment for example, when a student hears a word, then the lecturers can motivate and encourage students to figure out how to segment it into the phonemes that make up its pronunciation $(L 1 / G A)$. Showing students how to figure out the phoneme segments of new words is very useful strategy to engage students into the environment of learning is similar to the findings of Hoover and Tunmer (2017) when they examined the behaviour of students when they listened to words and then tried to pronounce it themselves and then write the words down. Also, mnemonic devices and memory aids can help students to remember the spelling rules as shared by many participants from Group A for example, the students must have memory aids and mnemonic devices as these will help students to spell words correctly (L4/GA). Mnemonic devices and memory aids help learners to learn more efficiently. For instance, $i$ comes before $e$ except after $c$; or two syllable words with stress on the last syllable and ending in a single vowel and consonant double the final consonant when a suffix is added and the stress remains the same (as in refer > referred). However, when the stress shifts or there are more syllables (as in refer > reference) there is no doubling of consonants.

Encouraging students to use personal or online dictionaries could be a useful way to look up into the correct spelling of a word this can be a way to motivate students to address their spelling problems as shred by a participant from Group A, individual learning tools can work wonders for helping students learn, like electronic dictionaries (L5/GA). Lin (2014) found individual learning tools that students can use outside the classroom or when they have an individual need, help them to develop their learning capabilities and capacities and take more responsibility for their learning; in this way, they can motivate and engage the students.

A participant from Group B shared his view regarding the learners' engagement as shown below.

The students must practice reading on many different topics in order to be familiar with the written of the spoken words.

$(L 1 / G B)$

Providing students with different interesting topics and encourage them to read in order to discover the correct spelling rules to eliminate their spelling errors. Lin's (2014), research revealed that spelling errors are more likely to be due to lack of understanding of the link between pronunciation and spelling and the significance of reading activities to help eliminate spelling errors.

The four English language skills are interrelated to each other in term of mastering any skill of them for example, students must practice free writing for example simple, short stories about their lives and try to check their spelling by referring to their lecturers or friends for help with words they are not sure of $(L 2 / G B)$. This response suggests free writing activities are important for improving the students' writing and eliminating spelling errors. Furió, Juan, Seguí, and Vivó, (2015) explored free writing activities by giving tasks to students and found that practicing free writing can help to reduce common spelling errors and it also improves students' grammar.

Another participant from Group B reported the following comment.

Students should be encouraged to leave and forget Arabic language system of pronunciation while writing in English.

$$
(L 5 / G B)
$$

Some teachers in Tabuk university believed their students try to pronounce English as if it were Arabic, that is, they do not understand that the two languages are based on different systems, so they become very confused. Dörnyei (2014) claims that learners must be provided with the specific system of a particular language and encouraged to focus on that rather than make comparisons with their L1.

A participant from Group C suggested that students should not be afraid to make spelling mistakes and should be encouraged to use any resource like the lecturer, friends or dictionaries to find the right way to spell words $(L 1 / G C)$. Getting the help from others in the same academic area like lecturers or friends in class can help reduce students' spelling problems, but perhaps the most important piece of advice is to not be afraid of making mistakes as it is only by making mistakes that we can learn. Morrow (2018) claims that in order to keep the students actively learning, the lecturers needs to take various initiatives, for example, getting them to use dictionaries or spelling checkers themselves when they need to, so that they are more actively involved in learning by finding their own mistakes and not simply being corrected and learning nothing.

A participant from Group $\mathrm{C}$ shared his view regarding the learners' engagement as it shown below.

While students read, they must look out for unfamiliar words and make a mental note of their spelling. Also, they must recognize which words are troublemakers and identify the tricky parts. 


\section{$(L 4 / G C)$}

The comment above suggests that students could become detectives while reading, to note mentally, or probably better still in writing in margin notes or notebooks, any words which seem troublesome and identify the parts they find tricky for instance consonant clusters like ght in thought, with the $g h$ silent, only /t/ pronounced, or $g h$ in words like enough, slough pronounced /f/. They could be encouraged to collect word families according to shared features like those mentioned. According to Richards (2015) educational institutions have to use multiple ways to address students' problems and offer several tools and methods that can help to reduce students' problems as some will find some tools - visual, auditory and so on - more useful than others, but they should be encouraged to try all of them to help them understand and remember unfamiliar words by assigning them to word families. Teachers can also use story-telling (for example, asking every student to create a 100-word story which must contain a number of key words like boundary, woods and white), crosswords, simulations and other strategies in order to encourage students to learn certain words or spellings by increasing their familiarity with them.

\section{Discussion}

The research participants from Tabuk University recommend and suggest various teaching strategies that could be implemented by educationalists and practiced by students. For example: seeking external helps from different sources, extra writing or spelling rules practicing and improving lecturers' pedagogical practice.

Devonshire and Fluck (2010) stated that spelling rules can be learnt if students make extra efforts. This perceptive of learning spelling through regular written practice in using the vocabulary of different subjects in context (rather than learning the spelling of new words individually, by heart, without a context). With the help of regular writing from the students and the continuous feedback from their lectures about the quality of students' writing in term of spelling as a main component of the writing skill, students can reduce their spelling errors. On other hand, lecturers must be provided with support and digital resources in order to guide the students' learning of the English language by more interactive means.

Reading skill and proofreading technique can be very helpful to reduce or eliminate the students spelling errors. This is supported by different researchers like Conrad (2008) who suggested that reading and critical evaluation or peer evaluation of scripts can be an effective way of identifying spelling mistakes also pronunciation errors. In the same vein, O'Brien (2015) revealed that proofreading is one of the most effective ways of improving spelling related issues.

Internet sources like online dictionaries, reading electronic newspapers or online quizzes can be helpful to learn new vocabularies, reduce the students' spelling errors and increase self-learning. El-Dakhs and Mitchell (2011) claimed that, regular use of dictionaries will increase the learners' vocabulary and improve their spelling.

Al-Sohbani and Muthanna (2013) found that students attributed their language difficulties to the kind of classroom activities use. However, spelling errors are due to lack of knowledge or not being taught the spelling rules for English. Since English language is considered to be orthographically deep in nature and spelling is not completely phonetic, correct spelling requires the application of spelling rules as recommended by Chen and Mohammed (2018).

The findings from the interviews showed that the students believed that the words on the lists had been learned in the classroom and tested weekly in order to review their progress. Golonka, Bowles, Frank, Richardson and Freynik (2014) suggest that teachers use etymology-based strategies, visual strategies, morphemic strategies or phonological strategies. A wide range of strategies and prompts offers different inputs and prompts to students so they could choose those which best fit to help them learn spellings more quickly.

\section{Conclusion}

There is multiple effective teaching or learning strategies to eliminate the Saudi spelling errors reported by the respondents or observed in this study, in particular, according to the respondents, lecturers' pedagogical practices, learners' engagement, practicing spelling and seeking external helps and sources can be considered as the most effective teaching or learning strategies to eliminate Saudi university students spelling errors.

\section{References}

Al-Jarf, R. (2007). Word order errors in English-Arabic translation. Middle East - Topics \& Arguments Journal, 52(2), 299-308. https://doi.org/10.7202/016072ar

Al-Khasawneh, F. M. (2014). Error analysis of written English paragraphs by Jordanian undergraduate students: A case study. International Journal of English Language, Literature and Humanities, 2(8), 85-100. 
Alkhatnai, M. (2012). The effect of TV captions on the comprehension of non-native Saudi learners of English. Sino-US English Teaching, 9(10), 1573-1579.

Al-Nafiseh, K. I. (2013). Collaborative writing and peer-editing in EFL writing classes. Journal of Emerging Trends in Educational Research and Policy Studies, 4(2), 236-245.

Al-Seghayer, K. (2014). The four most common constraints affecting English teaching in Saudi Arabia. International Journal of English Linguistics, 4(5), 17-26. https://doi.org/10.5539/ijel.v4n5p17

Al-Sobhi, B. M. S., Rashid, S. M., Abdullah, A. N., \& Darmi, R. (2017). Arab ESL secondary school students' spelling errors. International Journal of Education and Literacy Studies, 5(3), 16-23. https://doi.org/10.7575/aiac.ijels.v.5n.3p.16

Al-Sohbani, Y. \& Muthanna, A. (2013). Challenges of Arabic-English translation: The need for re-systematic curriculum and methodology reforms in Yemen. Academic Research International, 4(4), 442-450.

Al-Zuoud, K. M. \& Kabilan, M. K. (2013). Investigating Jordanian EFL students' spelling errors at tertiary level. International Journal of Linguistics, 5(3), 164-176. https://doi.org/10.5296/ijl.v5i3.3932

Arbib, M. A. (2005). From monkey-like action recognition to human language: An evolutionary framework for neurolinguistics. Behavioral and Brain Sciences, 28(2), 105-124. https://doi.org/10.1017/S0140525X05000038

Babayiğit, S., \& Stainthorp, R. (2010). Component processes of early reading, spelling, and narrative writing skills in Turkish: A longitudinal study. Reading and Writing, 23(5), 539-568. https://doi.org/10.1007/s11145-009-9173-y

Bisani, M., \& Ney, H. (2008). Joint-sequence models for grapheme-to-phoneme conversion. Speech Communication, 50(5), 434-451. https://doi.org/10.1016/j.specom.2008.01.002

Brice, R. G., \& Brice, A. E. (2009). Investigation of phonemic awareness and phonic skills in Spanish-English bilingual and English-speaking kindergarten students. Communication Disorders Quarterly, 30(4), 208-225. https://doi.org/10.1177/1525740108327448

Carney, E. (2012). A survey of English spelling. London: Routledge. https://doi.org/10.4324/9780203199916

Chen, I. J. (2017). Silent pauses in the oral reading task: Pausing patterns and reasons for pauses. International Journal of English and Literature, 8(3), 26-36. https://doi.org/10.5897/IJEL2016.0920

Conrad, N. J. (2008). From reading to spelling and spelling to reading: Transfer goes both ways. Journal of Educational Psychology, 100(4), 869-878. https://doi.org/10.1037/a0012544

Daif-Allah, A. S. (2012). Beliefs about foreign language learning and their relationship to gender. English Language Teaching, 5(10), 20-33. https://doi.org/10.5539/elt.v5n10p20

Devonshire, V., \& Fluck, M. (2010). Spelling development: Fine-tuning strategy-use and capitalising on the connections between words. Learning and Instruction, 20(5), 361-371. https://doi.org/10.1016/j.learninstruc.2009.02.025

Dörnyei, Z. (2014). The psychology of the language learner: Individual differences in second language acquisition. London, UK: Routledge. https://doi.org/10.4324/9781410613349

El-Dakhs, D., \& Mitchell, A. (2011). Spelling errors among EFL high school graduates (pp. 1-19). In Proceedings of the 4th Annual KSAALT Conference, paper presented in Al Khobar, Prince Mohammed Bin Fahad University. Saudi Arabia: KSAALT Quarterly.

Fresch, M. J. (2007). Teachers' concerns about spelling instruction: A national survey. Reading Psychology, 28(4), 301-330. https://doi.org/10.1080/02702710701545510

Furió, D., Juan, M. C., Seguí, I., \& Vivó, R. (2015). Mobile learning vs. traditional classroom lessons: A comparative study. Journal of Computer Assisted Learning, 31(3), 189-201. https://doi.org/10.1111/jcal.12071

Jahin, J. H. \& Idrees, M. W. (2012). EFL major student teachers' writing proficiency and attitudes towards learning English. Umm Al-Qura University Journal of Educational \& Psychologic Sciences, 4(1), 10-72.

Javid, C., \& Umer, M. (2014). Saudi EFL learners' writing problems: A move towards solution. Proceeding of the Global Summit on Education GSE 2014 (E-ISBN 978-967-11768-5-6), Kuala Lumpur, 4-5 March (pp. 164-180). Kuala Lumpur: WorldConferences.net. 
Javid, C. Z., Farooq, U., \& Umer, M. (2013). An investigation of Saudi EFL learners writing problems: A case study along gender-lines. Kashmir Journal of Language Research, 16(1), 179-203.

Kang, E. \& Han, Z. (2015). The efficacy of written corrective feedback in improving L2 written accuracy: A meta-analysis. The Modern Language Journal, 99(1), 1-18. https://doi.org/10.1111/modl.12189

Lin, C. C. (2014). Learning English reading in a mobile-assisted extensive reading program. Computers \& Education, 78(1), 48-59. https://doi.org/10.1016/j.compedu.2014.05.004

Liton, H. A. (2013). EFL teachers' perceptions, evaluations and expectations about English language courses as EFL in Saudi universities. Online Submission, 6(2), 19-34.

Meng, Y. Y. (2017). Written corrective feedback: A review of studies since Truscott (1996). Working Papers in TESOL and Applied Linguistics, 13(2), 69-84.

Moats, L. C. (2005). How spelling supports reading: And why it is more regular and predictable than you think. American Educator, 12(22), 42-43.

Morrow, C. K. (2018). Communicative language testing. New Jersey, US: John Wiley \& Sons, Inc. https://doi.org/10.1002/9781118784235.eelt0383

Mukminin, A., Ali, R. M., \& Ashari, M. J. F. (2015). Voices from within: Student teachers' experiences in English academic writing socialization at one Indonesian teacher training program. The Qualitative Report, 20(9), 1394-1407.

Pieretti, R. A., \& Roseberry-McKibbin, C. (2016). Assessment and intervention for English language learners with primary language impairment: Research-based best practices. Communication Disorders Quarterly, 37(2), 117-128. https://doi.org/10.1177/1525740114566652

Polio, C. (2012). The relevance of second language acquisition theory to the written error correction debate. Journal of Second Language Writing, 21(4), 375-389. https://doi.org/10.1016/j.jslw.2012.09.004

Rajab, H. (2013). Developing speaking and writing skills of L1 Arabic EFL learners through teaching of IPA phonetic codes. Theory and Practice in Language Studies, 3(4), 653-659. https://doi.org/10.4304/tpls.3.4.653-659

Reed, D. K. (2012). Why teach spelling? Portsmouth, NH: RMC Research Corporation, Center on Instruction.

Sarantakos, S. (2012). Social research. Hampshire, UK: Palgrave Macmillan.

Sawalmeh, M. H. M. (2013). Error analysis of written English essays: The case of students of the preparatory year program in Saudi Arabia. English for Specific Purposes World, 14(40), 1-17.

Sharma, V. K. (2015). How do productive skills of Saudi students affect EFL learning and teaching. Asian Journal of Humanities and Social Sciences, 3(2), 91-99.

Shintani, N., Ellis, R., \& Suzuki, W. (2014). Effects of written feedback and revision on learners' accuracy in using two English grammatical structures. Language Learning, 64(1), 103-131. https://doi.org/10.1111/lang.12029

Shukri, N. A. (2014). Second language writing and culture: Issues and challenges from the Saudi learners' perspective. Arab World English Journal, 5(3), 190-207.

Treiman, R. (2017). Learning to spell words: Findings, theories, and issues. Scientific Studies of Reading, 21(4), 265-276. https://doi.org/10.1080/10888438.2017.1296449

Wang, T., \& Jiang, L. (2015). Studies on written corrective feedback: Theoretical perspectives, empirical evidence, and future directions. English Language Teaching, 8(1), 110-120. https://doi.org/10.5539/elt.v8n1p110

\section{Copyrights}

Copyright for this article is retained by the author, with first publication rights granted to the journal.

This is an open-access article distributed under the terms and conditions of the Creative Commons Attribution license (http://creativecommons.org/licenses/by/4.0/). 